\section{Rothamsted Park Grass}

THE park grass plots at Rothamsted, laid down in 1856 and continued with little change in treatment ever since, afford a unique opportunity of studying the effects of long-continued manuring with different types of fertilizer on the yield and botenical composition of hay. The experiment was one of Dr. Winifred E. Brenchley's chief interests, and at the time of her death in 1953 she had nearly completed a revision of her monograph, published in 1924, "Manuring of Grassland for Hay", which dealt with the results up to 1919 , so as to include the data for the next thirty years. This revision is now being published (Rothamsted Experimental Station, Harpenden, Herts. 20s.) under the title "Rothamsted Park Grass, 1856-1949". Apart from some condensation and a few minor additions, little alteration has been made in Dr. Brenchley's revised text. The book provides the most recent data available on the botanical composition of the plots, as the regular hay analyses have been discontinued since 1949. Observations on the flora are, however, still being carried out, and the yields from two cuts of hay per annum recorded as before.

\section{Forestry in Japan}

IN Bulletin No. 102 of the Government Forest Experimental Station, Tokyo (Tokyo, 1957), Yoshio Matsushima, of the Government Forest Experimental Station, deals with some problems in Japanese forestry, from both the economic and scientific points of view. The investigations were carried out in the large province of Yoshimo, which contains several types of forest classified in Japan as natural forests, inaccessible and unworked, natural forests worked by the Government Forest Department, corporation forests, large private forests, small private forests, farm forests, and family forests. The unworked natural forests are situated on the tops and slopes of ridges where protection or a national safeguard is of first importance in the interests of water supplies and their continuity, which is well understood in Japan. Of the other types, the forests of the small landowner, farm forests and the family forests, the management is based on the intensive research carried out by the author and assistants from the research station. The smallest plots of land are not neglected, and expert advice on how to deal with them is available to the owners. The larger farm forests are not unknown in Yoshimo. They have labour to employ in the forest in the off-season for farming and supply their own requirements and sell the remainder at a profit. The interest and value of the author's investigations lie in the close study made of the small plots devoted to forestry by the small farmer and, above all, by the family. The labour for the first comes from the farm and is available when required. In the family forest plot the labour comes entirely from the family. On advice given they do the sowing or planting, supervise their small plot, and do the thinning and sales when necessary.

\section{'Ledercort'}

'LEDERCORT' is a new steroid with enhanced glucocorticoid and markedly reduced mineralocorticoid properties. Chemically, it is 9-alphafluoro-16 alpha-hydroxy-prednisolone. 'Ledercort' is claimed to be $10-40$ times more active than hydrocortisone, and 3-12 times more active than prednisolone, in glucocorticoid activity. In its anti- inflammatory activity, it is 10 times more active than hydrocortisone. Unlike these older steroids, 'Ledercort' does not produce retention of sodium and water, and often depresses rather than stimulates the appetite. Because of its reduced dosage, there is a lower incidence of other side effects such as peptic ulcer, epigastric distress, drug psychoses and diabetic state. It is applicable, therefore, to those conditions which have hitherto responded to the hydrocortisone derivatives (for example, rheumatoid arthritis, bronchial asthma, dermatoses, and allergic disorders). 'Ledercort' is supplied by Lederle Laboratories Division, of Cyanamid of Great Britain, Ltd., in 4-mgm. tablets.

\section{Artificial Earth Satellites}

Two lengthy papers on artificial Earth satellites have appeared recently, in the Irish Astronomical Journal of September-December 1957 and the Journal of the British Interplanetary Society of January-February 1958. The first of these is an interesting paper entitled "Artificial Satellites", by Dr. E. J. Öpik, based on a lecture to the Dublin meeting of the British Association last year. Dr. Öpik discusses most aspects of the subject, including a history of developments up to 1957 , a detailed description of satellite orbits and the conditions for visibility, an account of the effect of meteors and an outline of possible research programmes. It should be noted that, on p. 230, Table $9(b)$ and the formula for the motion of perigee are in error : the formula ought to be $p_{0}\left(5 \cos ^{2} i-1\right) / 2$, in Dr. Öpik's notation.

The second paper (J. Brit. Interplan. Soc., 16, 261; 1958), by D. E. Okhotsimskii and T. M. Eneev, is translated from Russian and has the title "Some Variation Problems connected with the Launching of Artificial Satellites of the Earth". This paper, which was presented at the Barcelona Astronautical Congress in September 1957, applies the calculus of variations to determine the optimum paths for satellite missiles during the powered climb from the Earth's surface. The optimum path in vacuo with constant gravity is established first, both for unrestricted propellant flow and for a specified flow. Then the problem is solved with a variable gravitational field and for a rotating Earth. Many of the results in the early part are familiar, but those in the later parts appear to be new.

\section{Marine Biological Association of the United Kingdom}

Tre Marine Biological Association of the United Kingdom has accepted a grant of $\$ 12,000$ from the Trustees of the Nuffield Foundation towards the cost of reconstructing the tanks of its aquarium at Plymouth. Part of the equipment of the Plymouth laboratory, which was opened in 1888, was a series of salt water tanks for experimental purposes. These tanks have always played a very essential part in the scientific activities of the laboratory, providing an opportunity of observing living animals under almost natural conditions. From the earliest days it was also realized that the tanks could fulfil a useful educational purpose ; the tank room was very soon opened to the public, and to-day it has 80,000 visitors annually.

\section{"Christopher Columbus" Prize for Communications}

THE city of Genoa has instituted, in commemoration of Christopher Columbus, a prize of five million lire. This is conferred yearly on someone who has made an outstanding contribution to communications during the past four years. For the prize there are 